\title{
Transgenic Expression of the Endothelin-B Receptor Prevents Congenital Intestinal Aganglionosis in a Rat Model of Hirschsprung Disease
}

\author{
Cheryl E. Gariepy, ${ }^{\star}$ S. Clay Williams, ${ }^{\star}$ James A. Richardson, ${ }^{\ddagger}$ Robert E. Hammer, ${ }^{\S}$ and Masashi Yanagisawa* \\ ${ }^{*}$ Howard Hughes Medical Institute, ${ }^{\star}$ Department of Pathology, ${ }^{\S}$ Department of Biochemistry, and ${ }^{\|}$Department of Molecular Genetics, \\ University of Texas Southwestern Medical Center, Dallas, Texas 75235-9050
}

\begin{abstract}
The spotting lethal rat, a naturally occurring rodent model of Hirschsprung disease, carries a deletion in the endothelin-B receptor $(E D N R B)$ gene that abrogates expression of functional EDNRB receptors. Rats homozygous for this mutation ( $s l$ ) exhibit coat color spotting and congenital intestinal aganglionosis. These deficits result from failure of the neural crest-derived epidermal melanoblasts and enteric nervous system (ENS) precursors to completely colonize the skin and intestine, respectively. We demonstrate that during normal rat development, the $E D N R B$ mRNA expression pattern is consistent with expression by ENS precursors throughout gut colonization. We used the human dopamine- $\beta$-hydroxylase $(D \beta H)$ promoter to direct transgenic expression of $E D N R B$ to colonizing ENS precursors in the $s l / s l$ rat. The $D \beta H-E D N R B$ transgene compensates for deficient endogenous $E D N R B$ in these rats and prevents the intestinal defect. The transgene has no effect on coat color spotting, indicating the critical time for $E D N R B$ expression in enteric nervous system development begins after separation of the melanocyte lineage from the ENS lineage and their common precursor. The transgene dosage affects both the incidence and severity of the congenital intestinal defect, suggesting dosage-dependent events downstream of EDNRB activation in ENS development. (J. Clin. Invest. 1998. 102:1092-1101.) Key words: spotting lethal rat • neural crest - Shah-Waardenburg syndrome - enteric nervous system
\end{abstract}

\section{Introduction}

Both enteric ganglion cells and epidermal melanocytes of vertebrates arise from the neural crest (1-3). Melanoblast precursors originate along the entire length of the neural crest and migrate through the dorsolateral pathway to colonize the skin

This work was presented in part October 31, 1997 at the annual meeting of the North American Society for Pediatric Gastroenterology and Nutrition.

Address correspondence to Masashi Yanagisawa, M.D., Ph.D., Howard Hughes Medical Institute, University of Texas Southwestern Medical Center, 5323 Harry Hines Blvd., Y5.210, Dallas, Texas 752359050. Phone: 214-648-5082; FAX: 214-648-5068: E-mail: afcsushi@ aol.com

Received for publication 13 May 1998 and accepted in revised form 27 July 1998

J. Clin. Invest.

(C) The American Society for Clinical Investigation, Inc. 0021-9738/98/09/1092/10 \$2.00

Volume 102, Number 6, September 1998, 1092-1101

http://www.jci.org
$(4,5)$. Enteric nervous system $(\mathrm{ENS})^{1}$ precursors are derived predominantly from the vagal neural crest, follow the ventral migratory pathway to enter the foregut in early embryos, and colonize the entire gut in a caudal progression $(3,6-9)$. To complete colonization, both cell types must survive, proliferate, spread over relatively long distances, establish the correct final residence, and differentiate. When vagal crest colonization of the gut is incomplete, the distal intestine is left aganglionic and functionally obstructed, leading to early death. Incomplete melanoblast colonization of the skin results in pigmentary abnormalities. The colonization processes of melanoblasts and ENS precursors are influenced by overlapping genetic pathways as evidenced by hereditary syndromes in which defects in development of both lineages appear together as localized pigment abnormalities associated with intestinal aganglionosis (10-14).

In mice, rats, horses, and humans, intestinal aganglionosis with associated pigmentary defects is caused by defective signaling through the endothelin-B receptor (EDNRB). Congenital distal intestinal aganglionosis in humans, Hirschsprung disease, occurs in one in 5,000 live born infants worldwide. Lossof-function mutations of the $E D N R B$ gene or the gene encoding one of its ligands, endothelin-3 (EDN3), cause Hirschsprung disease, sometimes associated with pigmentary abnormalities (Shah-Waardenburg syndrome) (15-21). Analogous mutations in $E D N 3$ and $E D N R B$ as well as disruption of the gene encoding the enzyme responsible for proteolytic activation of EDN3, $E C E-1$, cause intestinal aganglionosis and coat color spotting in mice (22-24). Mutation of the EDNRB gene was also recently demonstrated in a phenotypically similar syndrome of horses (overo-lethal-white-foal syndrome) (25).

The spotting lethal rat carries a naturally occurring 301-bp deletion in the $3^{\prime}$ end of the first exon of the EDNRB gene. The deletion encompasses the first two transmembrane spanning domains of the receptor and results in activation of a cryptic splice donor site 15 bp upstream of the deletion. The shortened transcript does not encode functional EDNRB (26). This autosomal recessive mutation $(s l)$ leads to reduced areas of pigmented skin and aganglionic intestinal obstruction. In most cases, the entire colon is aganglionic; only $10 \%$ of homozygous rats have ganglion cells in the proximal half of the colon $(12,27)$.

The endothelins are a family of related 21-amino acid peptides, EDN1, EDN2, and EDN3 $(28,29)$. There are two endothelin receptors, EDNRA and EDNRB, that are both G protein-coupled, heptahelical transmembrane proteins. EDNRA is selective for EDN1 and EDN2. EDNRB binds all three ligands with equal high affinity (30-33). The sites of EDNRB

1. Abbreviations used in this paper: $D \beta H$, dopamine- $\beta$-hydroxylase; EDNRB, endothelin-B receptor; ENS, enteric nervous system; RT, reverse transcriptase. 
and EDN3 expression in the developing human enteric nervous system were recently reported (34). In situ hybridization demonstrates $E D N R B$ expression beginning in the fourth to fifth week of gestation in stage 9-10 embryos. EDNRB mRNA is first detected in the neural crest cells and in the wall of the foregut diverticulum. Subsequently, $E D N R B$ is expressed in the migratory neural crest-derived cells along the ventral pathway and in a distinct population of cells within the wall of the gut proximal to the umbilical loop. $E D N R B$ mRNA in these cells colocalizes with tyrosine hydroxylase immunoreactivity, a marker of ENS precursors. EDNRB mRNA is not identified in the distal gut until after the sixth week of gestation. EDN3 is expressed in the gut mesenchyme from the stomach to the hindgut beginning in the fifth week of gestation. The majority of ENS precursors derived from the vagal crest express the catecholaminergic enzyme, dopamine- $\beta$-hydroxylase $(D \beta H)$ during intestinal colonization (35-38). In mice, they also express nlac $Z$ under the transcriptional control of a $5.8-\mathrm{kb}$ human $D \beta H$ promoter fragment. $D \beta H$-nlac $Z$ expression begins after the neural crest cells migrate to the foregut at $\sim \mathrm{E} 9.5$, and continues as the ENS precursors proceed to colonize the entire developing gut. Neither endogenous $D \beta H$ nor a $D \beta H$-nlacZ transgene are expressed in melanocytes or their precursors $(8$, $39)$. Therefore, the $D \beta H$ promoter is a valuable tool for targeting expression of heterologous gene products to ENS precursors during a well defined period in their development.

We describe the embryonic expression pattern of $E D N R B$ in the rat by in situ hybridization and present novel lines of transgenic rats in which the $D \beta H$ promoter is used to direct expression of $E D N R B$. We hypothesized that the expression of $E D N R B$ by enteric neuroblasts during their colonization of the developing gut would allow normal development of the ENS in the rat. The effect of the transgene in spotting lethal rats is studied to determine whether it can compensate for the deficient endogenous receptor. The results suggest critical quantitative aspects of $E D N R B$ expression and begin to define the timing and localization of $E D N R B$ expression sufficient for normal ENS development in the rat.

\section{Methods}

In situ hybridization. Sectional in situ hybridization for EDNRB mRNA in rat embryos was performed exactly as described previously (40), except the riboprobe was labeled with 33P-dCTP (Amersham Corp., Arlington, IL). The probe was a 293-bp fragment of the rat $E D N R B$ cDNA PCR-amplified from the $D \beta H-E D N R B$ transgene vector. The upstream primer was 5'-CAG GTA CGT TAC CTT GTA GGC-3' and the downstream primer was 5'-CTG CGG AGG TGA CCA AAC CT-3'. The reaction was cycled 35 times $(30 \mathrm{~s}$ at $94^{\circ} \mathrm{C}, 30 \mathrm{~s}$ at $55^{\circ} \mathrm{C}$, and $1 \mathrm{~min}$ at $72^{\circ} \mathrm{C}$ ). Sequencing confirmed that the fragment consisted of coding sequence of $E D N R B$ deleted in the sl mutation.

Production of $D \beta H-E D N R B$ transgenic rats. A $1.89-\mathrm{kb}$ XhoI fragment containing the entire coding sequence, $394 \mathrm{bp}$ of $5^{\prime}$-translated sequence, and $368 \mathrm{bp}$ of $3^{\prime}$-untranslated sequence was isolated from the rat EDNRB cDNA (GenBank X57764). This fragment was inserted into a $D \beta H$-cDNA expression vector by ligation after BamHI digestion, blunting, and phosphatase treatment. This vector is identical to that used to produce $D \beta H-N G F$ (41) and $D \beta H$-nlac $Z$ (39) transgenic mice. It contains a $5.8-\mathrm{kb}$ fragment from the $5^{\prime}$ portion of the human $D \beta H$ gene fused to the first intron of the rat insulin gene. The intron is separated by a BamHI site from the $3^{\prime}$-untranslated sequences of the mouse protamine gene. The orientation of the insert was confirmed by restriction enzyme digestion and the resulting plasmid was amplified, isolated, and cut with Not I to excise the transgene. Transgenic rats were generated as previously described (42).

Identification and quantification of transgene. Transgenic animals were identified and the transgene quantified in the founder rats and their progeny by dot-blot hybridization of genomic DNA isolated from tail biopsies (42). Duplicate membranes were made. One membrane was probed with a $2.2-\mathrm{kb}$ SstII fragment of the human $D \beta H$ promoter cut from the transgene vector. The other membrane was probed with a fragment of the murine $\beta$-actin gene to serve as a loading control. A phosphorimager (Molecular Dynamics, Sunnyvale, CA) was used to quantitate the signal from both blots, and the ratio of transgene to $\beta$-actin signal was used to access whether the animal was homozygous or hemizygous for the transgene.

Documentation of transgene expression by reverse transcriptase (RT)-PCR and Northern blot analyses. Total RNA was extracted from the adrenal glands, kidney, lung, heart, brain, small intestine, and large intestine using RNA STAT-60 reagents (Tel-Test, Friendswood, TX) from wild-type, $s l /+, s l / s l$ transgene hemizygous, and $s / / s l$ transgene homozygous adult rats from the transgenic line 1. Total RNA was prepared similarly from adrenal glands from the transgenic line 2. For RT-PCR confirmation of transgene expression, first strand cDNA was synthesized with oligo(dT)12-18 primers by using SuperScript reverse transcriptase as recommended by the manufacturer (GIBCO BRL, Gaithersburg, MD). Oligonucleotide primers (upstream, 5'-GCA GGA ATT CGA TAT CAA GC-3'; downstream, 5'-TGG AGT TCC CGA TGA TGC CT-3'), which flanked the intron in the transgene were used to PCR amplify the $D \beta H-E D N R B$ transgene. The reaction was cycled as described above. The resulting 500-bp product (as opposed to the 800-bp genomic DNA-derived product) was isolated electrophoretically in $1.4 \%$ agarose and visualized by ethidium bromide staining.

Northern blot analysis was carried out as described (43). $20 \mu \mathrm{g}$ per lane of total RNA from each tissue was loaded. The probe was a DNA fragment corresponding to the $E D N R B$ deletion in the $s l$ rat described above (in situ hybridization).

Genotyping of $+/+$, s $/++$, and sl/sl rats by $P C R$. To differentiate the sl EDNRB from the wild-type EDNRB, PCR was performed on DNA isolated from tail biopsy specimens. After the biopsy was completely digested in $4 \mathrm{ml} \mathrm{SNET} \mathrm{(20} \mathrm{mM} \mathrm{Tris,} \mathrm{pH}$ 8.0, $5 \mathrm{mM}$ EDTA, $1 \%$ SDS, $400 \mathrm{mM} \mathrm{NaCl}$ ) containing $250 \mu \mathrm{g} / \mathrm{ml}$ proteinase $\mathrm{K}, 200 \mu \mathrm{l}$ was used for DNA preparation (Tissue DNA Preparation Kit; QIAGEN, Chatsworth, CA), as recommended by the manufacturer except that the final product was diluted 1:10 with $10 \mathrm{mM}$ Tris ( $\mathrm{pH}$ 8.5) before PCR amplification. Primers flanked the $s l$ deletion (upstream, 5'AGC CGG TGC GGA CGC GCC TT-3'; downstream, 5'-CAC GAC TTA GAA AGC TAC AC-3') to amplify a 650-bp fragment from the wild-type $E D N R B$ allele and a 350-bp fragment from the $s l$ $E D N R B$ allele. This reaction does not amplify the transgene $E D N R B$ because the downstream primer is within the first intron. The reaction was cycled as described above. The fragments were separated in a $1.4 \%$ agarose gel and visualized with ethidium bromide staining.

Acetylcholinesterase staining. Under Nembutal anesthesia (60 $\mathrm{mg} / \mathrm{kg}$ intraperitoneal), rats were perfused from the left ventricle with saline containing $0.375 \mathrm{U} / \mathrm{ml}$ hyaluronidase (Sigma Chemical Co., St. Louis, MO). The entire colon was then removed, sectioned along the mesenteric boarder, and rinsed with saline/hyaluronidase. It was evenly stretched in all directions, pinned to a support media, and fixed overnight at $4^{\circ} \mathrm{C}$ in $4 \%$ paraformaldehyde containing $1 \% \mathrm{CaCl}_{2}$. The segment was rinsed in a $5 \%$ sucrose/PBS solution at $4^{\circ} \mathrm{C}$ for $24 \mathrm{~h}$. After the mucosa and submucosa were carefully scraped off under a dissection microscope, the segment was incubated in $15 \mathrm{mM}$ sodium citrate $/ 0.05 \%$ acetylthiocholine iodide $/ 3 \mathrm{mM}$ copper sulfate $/ 5 \mathrm{mM}$ tetraisopropyl-pyrophosphoramide $/ 64 \mathrm{mM}$ sodium acetate $1 \times$ Triton (Triton Ultra; Sigma Chemical Co.) $/ 0.5 \mathrm{mM}$ potassium ferricyanide at $37^{\circ} \mathrm{C}$ for $3 \mathrm{~h}$, and then rinsed with PBS. It was dehydrated in $40 \%$ glycerol for $5 \mathrm{~min}$ and transferred to microscope slides with coverslips using gelatin glycerol-mounting media. 
Statistical analysis. Relevant data was processed by InStat (GraphPAD Software for Science, San Diego, CA). Data regarding the incidence of intestinal obstruction in $s / / s l$ rats homozygous or hemizygous for the transgene was subjected to the Fisher exact test. Lifespan data was subjected to the Mann-Whitney test. Mean values are reported \pm SEM and $P<0.05$ was considered significant.

\section{Results}

Expression patterns of EDNRB $m R N A$ in rat embryos. We examined the distribution of $E D N R B$ mRNA in rat embryos by in situ hybridization at E11.5, E13.5, and E15.5, when intestinal colonization by vagal neural crest cells takes place (Fig. 1)
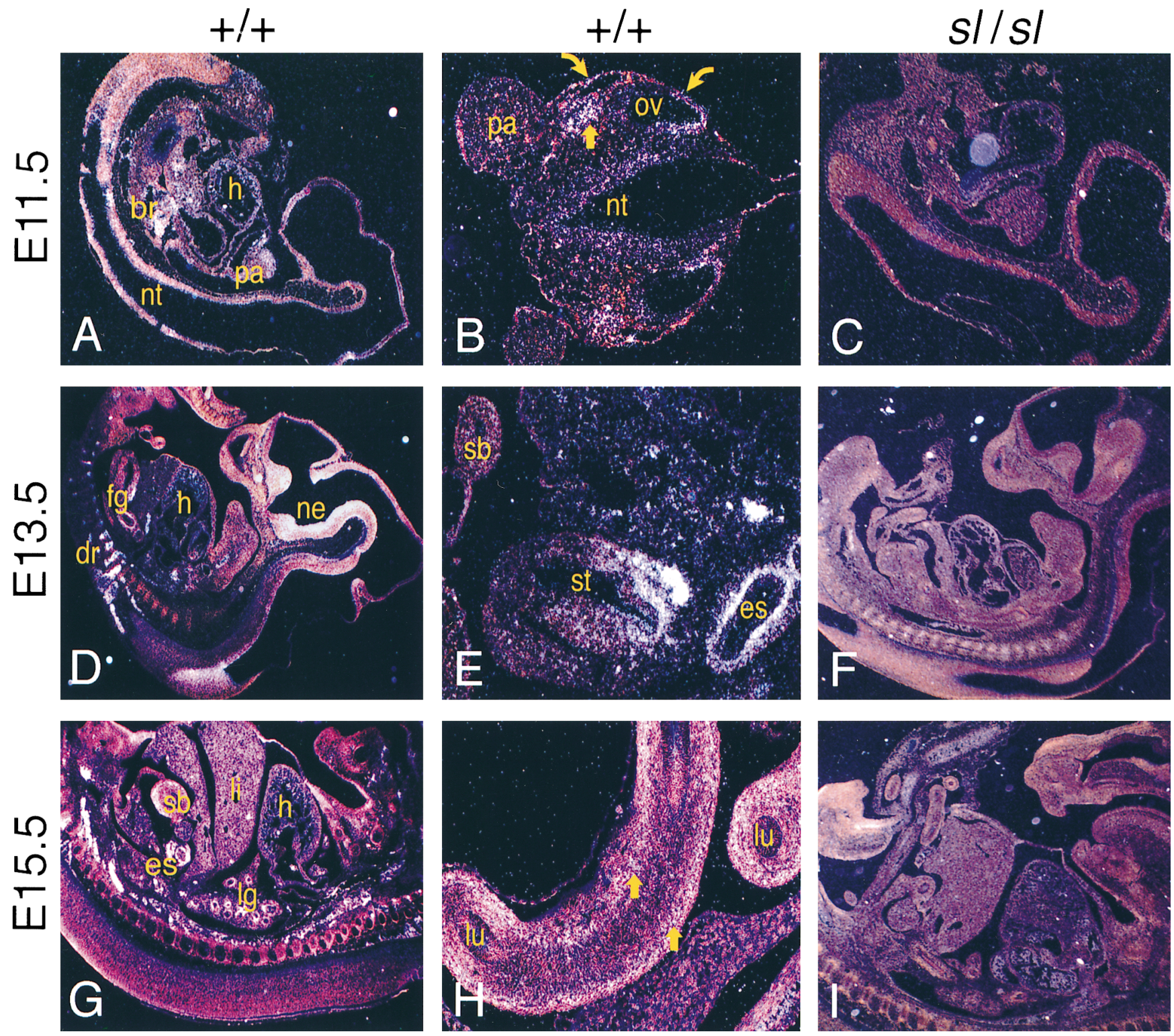

Figure 1. EDNRB expression in wild-type rat embryos visualized by in situ hybridization. ( $A$ ) Parasagittal section at E11.5. EDNRB mRNA is detected in the neuroepithelium lining the neural tube $(n t)$, the bronchus $(b r)$, pharyngeal arch mesenchyme $(p a)$, and the endothelium of the heart $(h)$, aortic sac, dorsal aorta, and umbilical vessels. $(B)$ Transverse section at E11.5. EDNRB mRNA is detected in the neural tube $(n t)$ and in a pattern consistent with migrating neural crest-derived cells (arrow). The otic vesicle (ov) and pharyngeal arch ( $p a)$ are indicated. Note the expression along the dorsolateral pathway of neural crest migration (curved arrows). ( $D$ and $E$ ) Parasagittal section at E13.5. In $D$, expression of $E D N R B$ mRNA is demonstrated in the dorsal root ganglia as well as the nerves of the dorsal roots $(d r)$ and their branches, the ventricular zone neuroepithelium (ne), sympathetic ganglia, and vascular endothelium (including the endothelium of the heart, $h$ ). The foregut $(f g)$ is also indicated. In the gut, $(E)$, expression is demonstrated in the esophagus $(e s)$ and stomach $(s t)$, whereas no expression is seen in the small bowel $(s b)$. $(G$ and $H)$ Parasagittal section at E15.5. $G$ shows EDNRB mRNA detected in the sympathetic chain, vascular endothelium (as in the heart, $h$ ), mesenchyme of the pancreas, and peribronchiolar mesenchyme $(l g)$. The esophagus $(e s)$ and the small bowel $(s b)$ show a ring pattern of expression. The liver ( $l i)$ is also indicated. Higher magnification of the more distal gut in $H$ demonstrates $E D N R B$ expression in cells subjacent to the developing circular muscle layer (arrows), and in scattered cells within the circular muscle layer and submucosa. The lumen $(l u)$ of the developing gut is indicated. ( $C, F$, and $I$ ) Parasagittal sections of age matched $s l / s l$ embryos. No signal is detected. The probe corresponds to the $3^{\prime}$ end of the first exon of rat $E D N R B$. 
$(44,45)$. In E11.5 embryos, no EDNRB expression was detected in the foregut. Expression was noted in the ventricular zone of neuroepithelium, the developing bronchus, first and second pharyngeal arch mesenchyme, mesenchyme of the liver premordium, and surrounding the neural tube and endothelium of the heart, aortic sac, dorsal aorta, and umbilical vessels. $E D N R B$ expression was also detected along the dorsolateral neural crest migration pathway, consistent with expression by putative melanoblasts (Fig. 1 B). E13.5 embryos showed $E D N R B$ expression in a circumferential population of cells in the foregut whereas no expression was identified in adjacent midgut sections (Fig. $1 E$ ). At this stage, expression was also detected in the dorsal root ganglia, nerves of the dorsal roots and their branches, sympathetic ganglia, hepatic large vessel endothelium, and ventricular zone neuroepithelium, particularly the tegmental neuroepithelium and near the hypothalamus, mammillary bodies, and medulla. In E15.5 embryos, the entire gut showed circumferential $E D N R B$ expression (Fig. 1 $\mathrm{H})$. Other tissues that showed EDNRB expression in the E15.5 rat embryo included the ventricular zone of the neuroepithelium, especially in the fourth ventricle near the pons, the ganglia of the sympathetic chain, vascular endothelium, mesenchyme of the pancreas, and peribronchiolar mesenchyme.
No signal was detected in non-transgenic $s / / s l$ embryos at E11.5, E13.5, or E15.5, confirming the specificity of the hybridization.

$D \beta H$-EDNRB expression in wild-type and sl/sl rats. $D \beta H$ $E D N R B$ transgenic rats were produced to investigate the influence of targeted $E D N R B$ expression on enteric nervous system development in wild-type and $s / / s l$ embryos (Fig. $2 A$ ). The latter lack endogenous $E D N R B$ and never develop ganglia in the distal colon as a consequence. In mice, the human $D \beta H$ promoter directs expression to cells derived from the vagal neural crest from the stage at which they begin to colonize the foregut. In addition, transgene expression occurs in mice in a subset of neuronal precursors in the peripheral and central nervous systems, but not in melanocytes or their precursors and not in vagal crest cells before their migration to the gut (39).

Two independent lines of $D \beta H-E D N R B$ rats were created which carry $\sim 40$ (line 1 ) and 70 (line 2 ) copies of the transgene as estimated by hybridization with radiolabeled probes specific for the human $D \beta H$ promoter. Expression was documented in adult adrenal glands by RT-PCR (Fig. $2 B$ ) and in several adult tissues by Northern blot analysis. The latter analysis showed that in the colon, healthy adult $s / / s l$ rats hemizygous for the transgene in line 1 had a significantly lower level

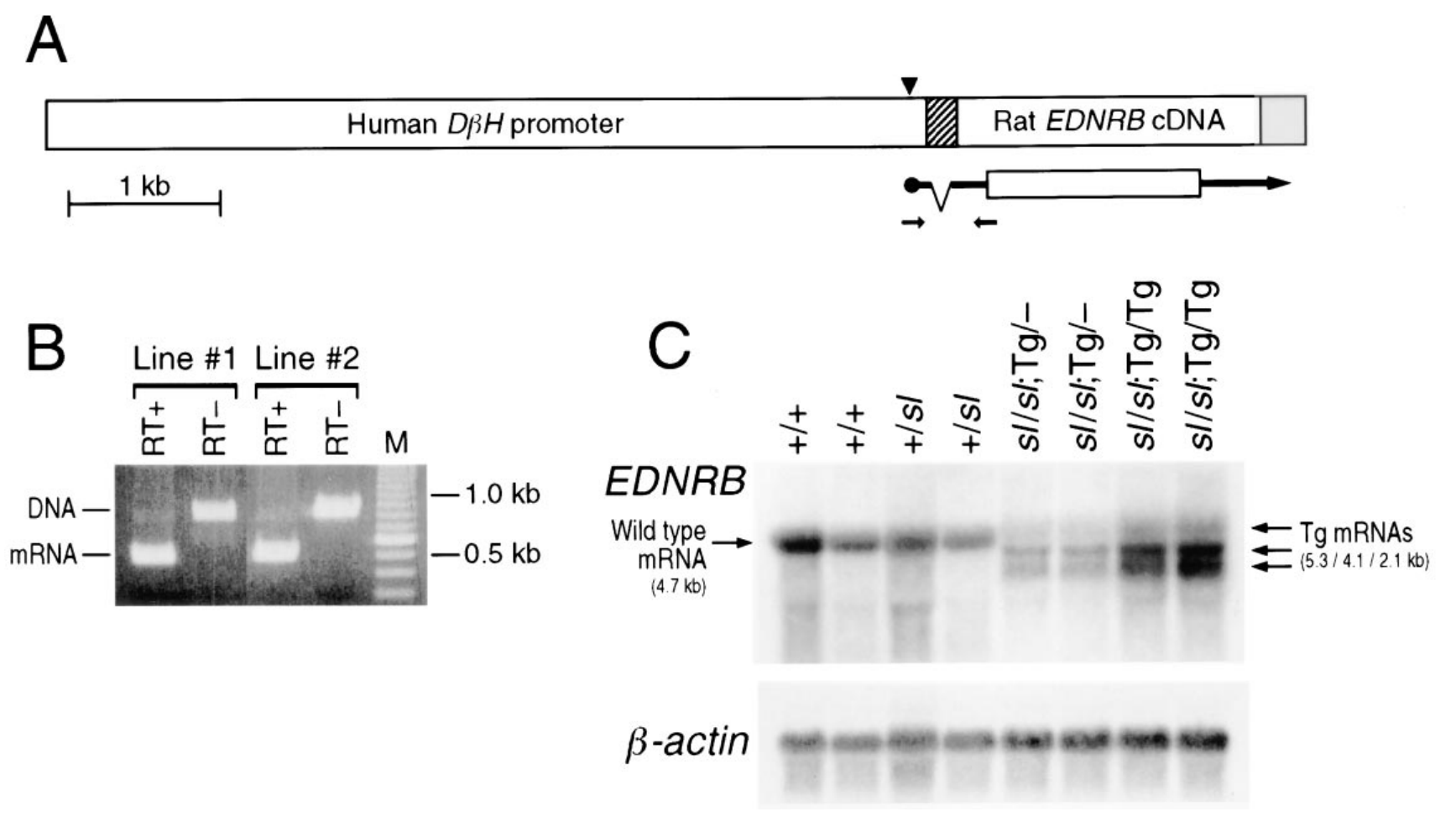

Figure 2. $D \beta H-E D N R B$ transgene construction and demonstration of expression. (A) The entire coding sequence of rat $E D N R B$ along with 394 bp of $5^{\prime}$-translated sequence and 368 bp of $3^{\prime}$-untranslated sequence was inserted into a $D \beta H$-cDNA expression vector downstream of a 5.8 -kb fragment from the $5^{\prime}$ portion of the human $D \beta H$ gene fused to the first intron of the rat insulin gene. The intron is separated by a BamHI site from the 3'-untranslated sequences of the mouse protamine gene. (B) RT-PCR confirmation of transgene expression. Oligonucleotide primers that flanked the intron in the transgene were used to PCR amplify the $D \beta H$-EDNRB transgene. Reverse transcription before amplifications yields a 500-bp product, as opposed to the 800-bp genomic DNA-derived product obtained in the absence of reverse transcription. (C) Northern blot analysis was carried out using $20 \mu \mathrm{g}$ per lane of total RNA from the adult rat colon using standard methods. The probe was an EDNRB fragment corresponding to the deletion in the $s l$ rat. Genotypes are listed above. Rats are non-transgenic unless indicated. Ribosomal RNA bands were used as size standards. The wild-type transcript (demonstrated in the four left lanes) is $4.7 \mathrm{~kb}$ and is not detected in $s / / s l$ rats. Three transgene transcripts (presumably due to alternative transcription initiation and/or termination) are demonstrated at 2.1, 4.1, and 5.3 kb. Autoradiography was exposed for $4 \mathrm{~d}$ for the $E D N R B$ probe and $1 \mathrm{~h}$ for the $\beta$-actin probe. 
of $E D N R B$ expression than non-transgenic $s /$ + rats (Fig. $2 C$ ). Expression was also detected in the adult adrenal, lung, brain, and, to a lesser extent, in the small intestine, kidney, and heart (data not shown). Northern analysis in transgenic line 2 showed the same tissue distribution of transgene expression. In both lines, the transgene produced three major transcripts ranging in size from 2.1 to $5.3 \mathrm{~kb}$. The endogenous wild-type transcript of $4.7 \mathrm{~kb}$ was undetectable in $s / / s l$ transgenic rats. In wild-type rats, the transgene had no perceptible phenotypic effect in either line. Transgenic animals carrying the wild-type endogenous $E D N R B$ were fertile and showed normal coat pigmentation. The architecture of the myenteric plexus in adult $s l /+$ transgenic and non-transgenic rats was normal and identical in wholemount preparations stained histochemically for acetylcholinesterase activity (data not shown).

The pattern of $D \beta H-E D N R B$ transgene expression was studied in $s l / s l$ transgenic line 1 rat embryos at E11.5, E13.5, and E15.5 (Fig. 3). The probe consisted of the fragment of $E D N R B$ coding sequence deleted in the $s l$ mutation. At E11.5, expression was detected in the foregut (Fig. $3 A$ ). In addition, strong expression was seen in the head mesenchyme and in the ventricular zone of the neuroepithelium. A lower level of expression was also identified in the sclerotome of the somites, pharyngeal arch mesenchyme, facial and acoustic ganglia, and otic vesicles. EDNRB expression was not detected along the dorsolateral neural crest migration pathway, consistent with an absence of transgene expression in melanoblasts (Fig. $3 \mathrm{~B}$ ). Expression was detected at E13.5 in the stomach and midgut (Fig. $3 \mathrm{D}$ ). The stomach showed expression in a distinct population of cells subjacent to the forming lamina propria. E13.5 embryos also showed transgene expression in the dorsal root ganglia, ventricular neural epithelium, perineural tissue of the dorsal roots, core mesenchyme of the tongue, and in the region of the developing meninges. The liver showed expression in a scattered, distinct population of cells probably representing a hematopoietic lineage. Finally, at E15.5, all gut sections showed two concentric rings of distinct transgene expressing cells (Fig. 3 F). The outer layer of expressing cells was clearly localized between the developing muscle layers of the gut, whereas the inner layer was in the submucosa. No expression
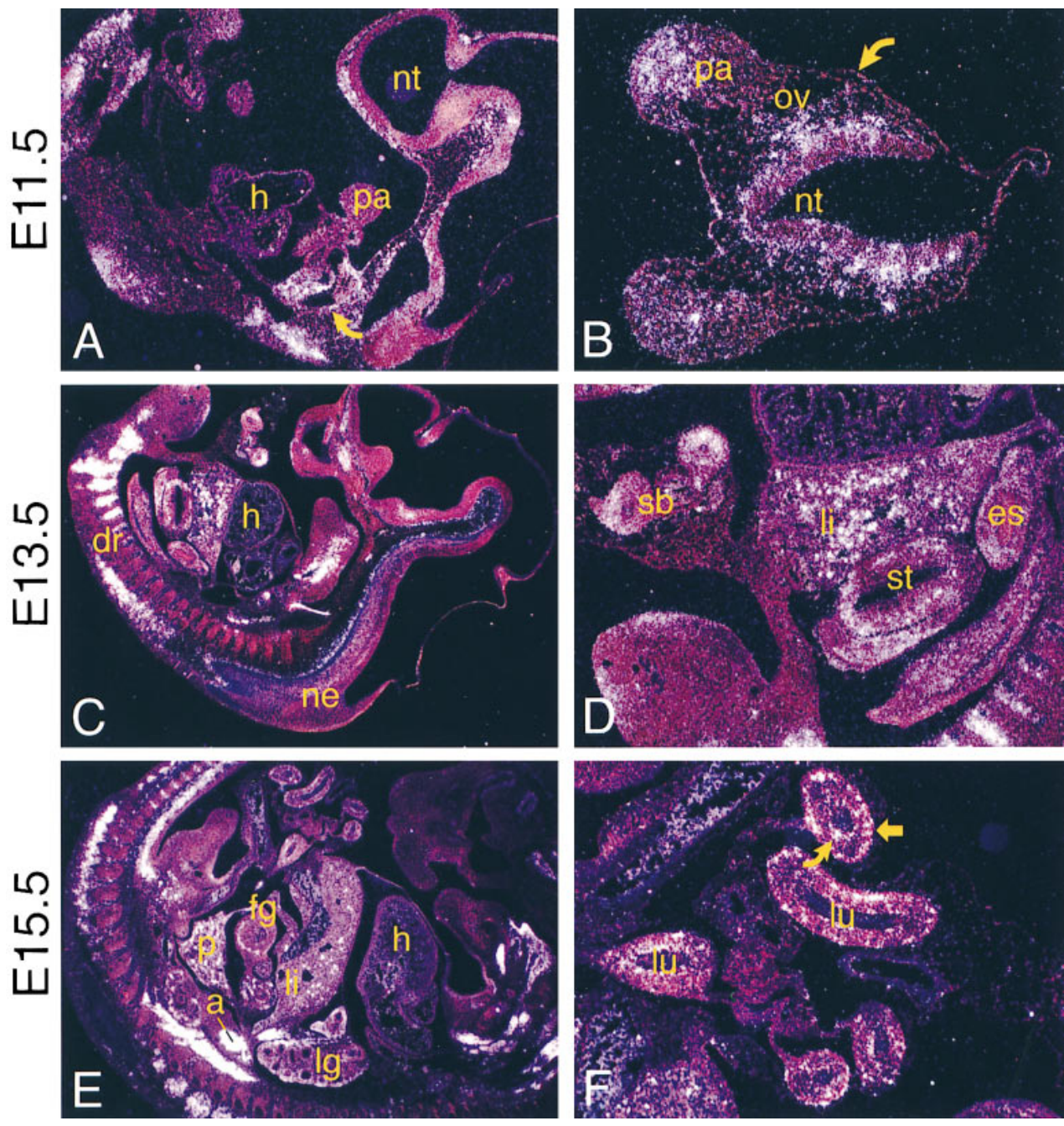

Figure 3. Expression of the $D \beta H$ $E D N R B$ transgene in $s l / s l$ rat embryos visualized by in situ hybridization. (A) Parasagittal section at E11.5. EDNRB mRNA is detected in the head mesenchyme, neuroepithelium lining the neural tube (nt), and foregut (curved arrow). The heart $(h)$ and the pharyngeal arch $(p a)$ are indicated. $(B)$ Transverse section at E11.5. EDNRB mRNA is detected in the neural tube (nt) with increased expression at the lateral margins and in the pharyngeal arch mesenchyme ( $p a)$. The otic vesicle $(o v)$ is also indicated. Note the absence of expression along the dorsolateral pathway of neural crest migration (curved arrow; compare with Fig. $1 B)$. $(C$ and $D$ ) Parasagittal section at E13.5. $C$ shows expression of $E D N R B$ mRNA in the dorsal root ganglion and the perineural tissue of the dorsal roots $(d r)$. It is also seen in the neural epithelium (ne) and in the region of the developing meninges. The heart is indicated (h). Higher magnification of the gut in $D$, shows that the stomach $(s t)$ and esophagus (es) express the transgene in a population of cells subjacent to the forming lamina propria. Adjacent small bowel sections $(s b)$ also show expression, particularly in the antimesenteric aspect. $(E$ and $F$ ) Parasagittal section at E15.5. EDNRB mRNA is detected $(E)$ in the adrenal $(a)$,

dorsal root ganglia, a small population of cells in the liver $(l i)$, the meninges, a subpopulation of cells in the pancreas $(p)$, perineural tissues, and subpleural mesenchyme $(\mathrm{lg})$. Location of the heart $(h)$ is also indicated. All gut sections in $F$ demonstrate two concentric rings of cells expressing the transgene. The outer layer (arrow) lies between the developing circular and longitudinal muscle layers, and the inner layer (curved arrow) is localized in the submucosa. The lumen $(l u)$ of the developing bowel is indicated. The probe corresponds to the portion of the EDNRB cDNA that is deleted in the $s l$ mutation. 
was seen in the smooth muscle layers of the gut. Expression persisted in the dorsal root ganglia, motor nuclei in the midbrain and pons, a scattered population of cells in the liver, and the meninges. Expression was also identified in the adrenal, various developing skeletal muscle groups, a distinct population of non-epithelial cells in the pancreas, perineural tissues, subpleural mesenchyme, and rare cells in the renal ductular epithelium and ureteric bud.

$D \beta H-E D N R B$ expression in sl/sl embryos prevents intestinal aganglionosis in a dose-dependent manner. Crosses of the $D \beta H$-EDNRB transgenic rats with $s l /+$ rats led to the production of $s / / s l$ transgenic pups. The coats of $D \beta H$-EDNRB transgenic $s / / s l$ rats were indistinguishable from non-transgenic $s / / s l$ littermates (Fig. 4). However, whereas all of the non-transgenic animals died spontaneously with intestinal obstruction before or shortly after weaning, the vast majority of transgenic $s l / s l$ animals from both lines survived and grew normally. Of 74 animals hemizygous for the transgene in the line 1 , only 15 developed megacolon (Fig. 5). The incidence of disease decreased further to 2 of $41 \mathrm{sl} / \mathrm{sl}$ rats homozygous for the transgene (relative risk 1.47, $P=0.029$ ). Whereas the mean age at
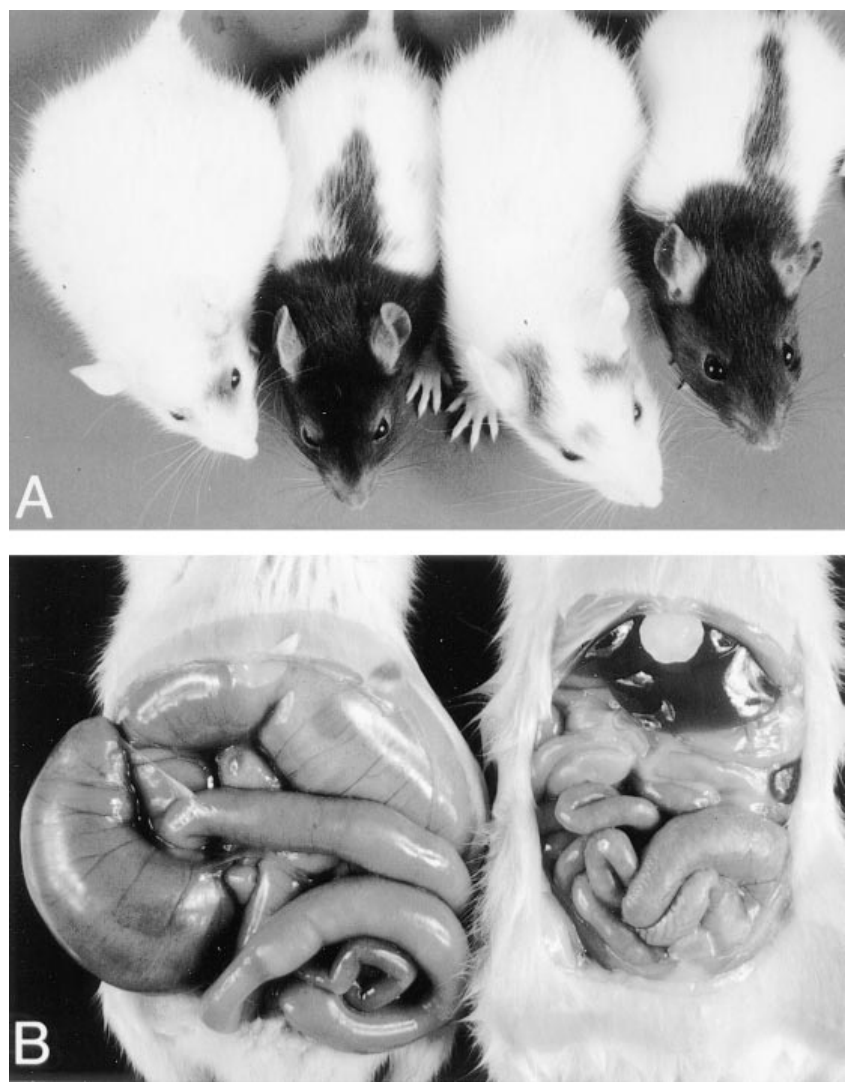

Figure 4. Phenotype of $s / / s l$ transgenic rat. (A) 4-wk-old $s / / s l$ rats carrying the transgene (third from the left) are almost entirely white and indistinguishable on the basis of coat color from non-transgenic $s / / s l$ rats (far left). However, the non-transgenic rats are easily distinguished on the basis of poor growth and severe abdominal distension beginning in the first weeks of life. The genotypes of these animals (from left to right) are: $s / / s l$ non-transgenic, $s l /+$ non-transgenic, $s l / s l$ transgenic, and $s l+$ transgenic. $(B)$ Gross intestinal phenotype in an $s l / s l$ non-transgenic (left) and $s / / s l$ transgenic $(r i g h t)$. Note the marked distention of the bowel due to distal intestinal obstruction in the nontransgenic animal.

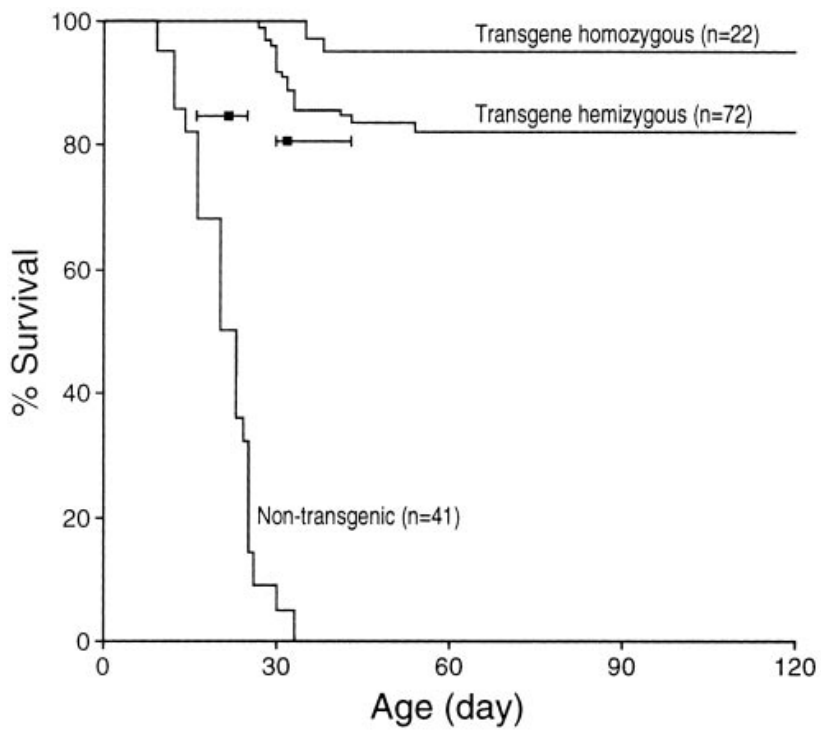

Figure 5. Cumulative survival of $s l / s l$ rats. The percentage of $s l / s l$ rats surviving through postnatal day 120 is shown. All deaths were the result of obstruction due to intestinal aganglionosis. At day $120,95 \%$ of transgene homozygous $s l / s l$ rats survived versus $82 \%$ of transgene hemizygous $s l / s l$ rats $(P=0.029)$. The error bars indicate the median and 25-75th percentile for the age of death of those animals developing intestinal obstruction in the $s / / s l$ non-transgenic and $s l / s l$ transgene hemizygous groups. The median survival of $s l / s l$ non-transgenic animals was 21.5 (16-25) d, whereas the median survival of obstructed $s l / s l$ transgene hemizygous animals was $32(30-43) \mathrm{d}(P<$ 0.0001).

severe illness or death in the non-transgenic $s l / s l$ rats was $21 \pm$ $1 \mathrm{~d}$, the mean age at severe illness or death for the line 1 transgenic (hemizygous) $s l / s l$ rats was $38 \pm 3 \mathrm{~d}(P<0.0001$; Fig. 5). Furthermore, the minority of transgenic $s / / s l$ rats that eventually developed intestinal obstruction exhibited an obviously different phenotype from non-transgenic $s / / s l$ rats. They typically had fecal soiling of the base of the tail and anus and a visible large stool collection in the rectum. A rectal mass was never observed in non-transgenic $s / s l$ rats. Grossly, when intestinal obstruction occurred, it appeared to occur much more distally in the transgenic $s / / s l$ rats than non-transgenic $s l / s l$ rats. Of $10 s / s l$ transgenic rats that developed intestinal obstruction, none had microcolon, which is the gross anatomic correlation of an absence of ganglion cells in the entire colon and is the typical finding in non-transgenic $s / / s l$ rats, two had narrowing of the distal colon $(<2 \mathrm{~cm})$, and eight had distension of the entire length of the colon, with stool filling the bowel lumen to the anus. Histologic study of the large intestine from healthy $D \beta H-E D N R B$ transgenic $s / / s l$ rats demonstrated complete colonization by ganglion cells. The myenteric plexus of the "rescued" animals appeared indistinguishable from that of wild-type animals in wholemount preparations stained for acetylcholinesterase activity (Fig. 6). Transgenic $s / / s l$ rats with intestinal obstruction showed an aganglionic colon segment significantly shorter than is typical of $s / / s l$ non-transgenic rats. Wholemount acetylcholinesterase staining showed total intestinal aganglionosis in 5 of 5 non-transgenic $s / s l$ rats (Fig. 7). In contrast, similar preparations from four non-rescued transgenic $s l / s l$ rats showed distal aganglionosis of $<15 \%$ of the colon, confirming 

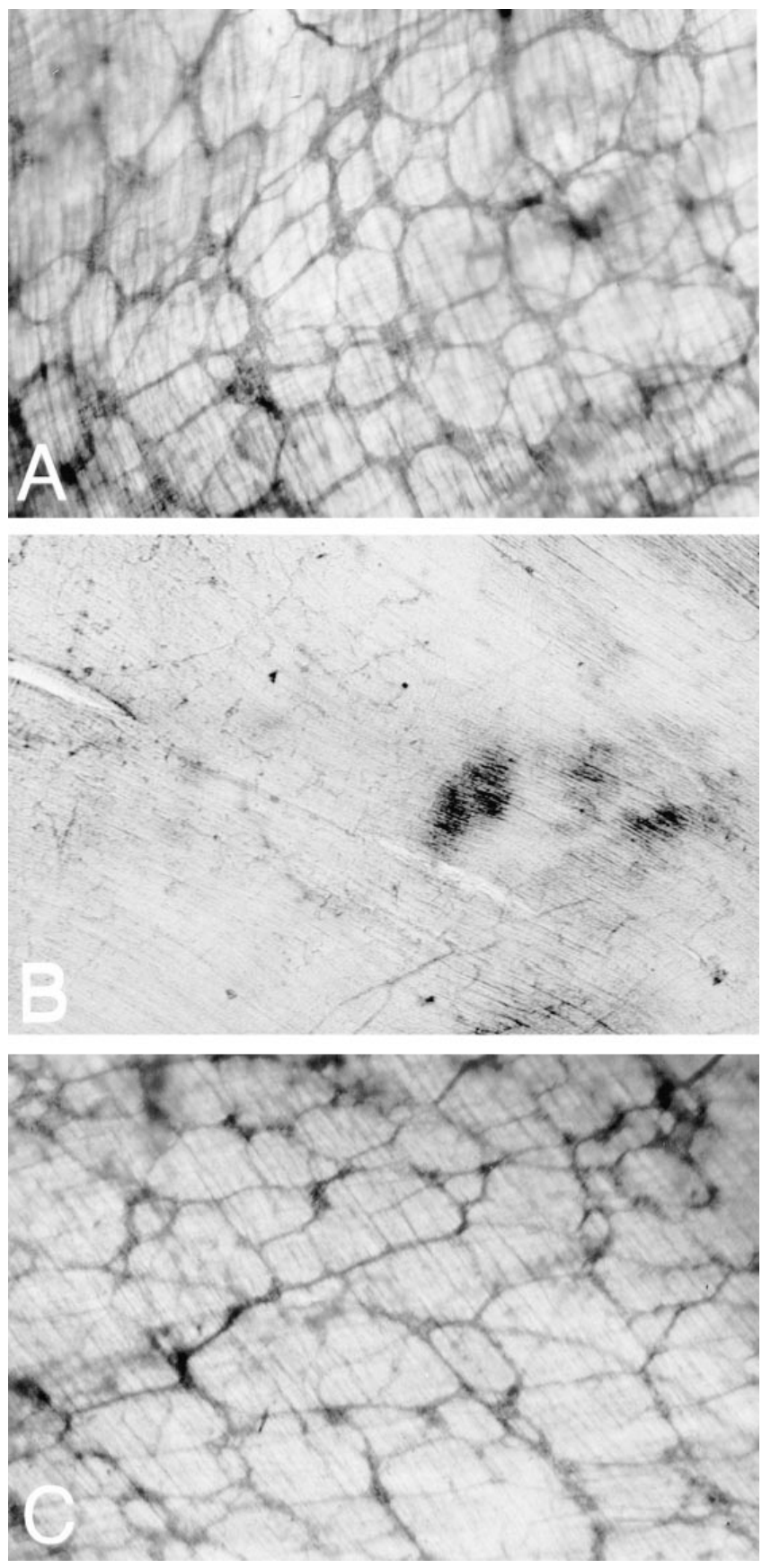

Figure 6. Acetylcholinesterase staining in the distal hindgut. $(A)$ Acetylcholinesterase histochemistry in the rectum of a wild-type rat demonstrates the normal fine meshwork of the myenteric plexus. $(B)$ The same technique applied to the rectum of an $s / / s l$ non-transgenic rat shows a complete absence of the normal myenteric network. (C) Staining in a healthy $s l / s l$ transgenic rat demonstrates a myenteric plexus indistinguishable from wild-type.

the gross anatomical impression of shorter segment aganglionosis in these rats.

\section{Discussion}

The expression pattern of EDNRB in the embryonic rat gut correlates with its expected role in ENS development. Once they leave the neural crest, cells destined to form enteric ganglion
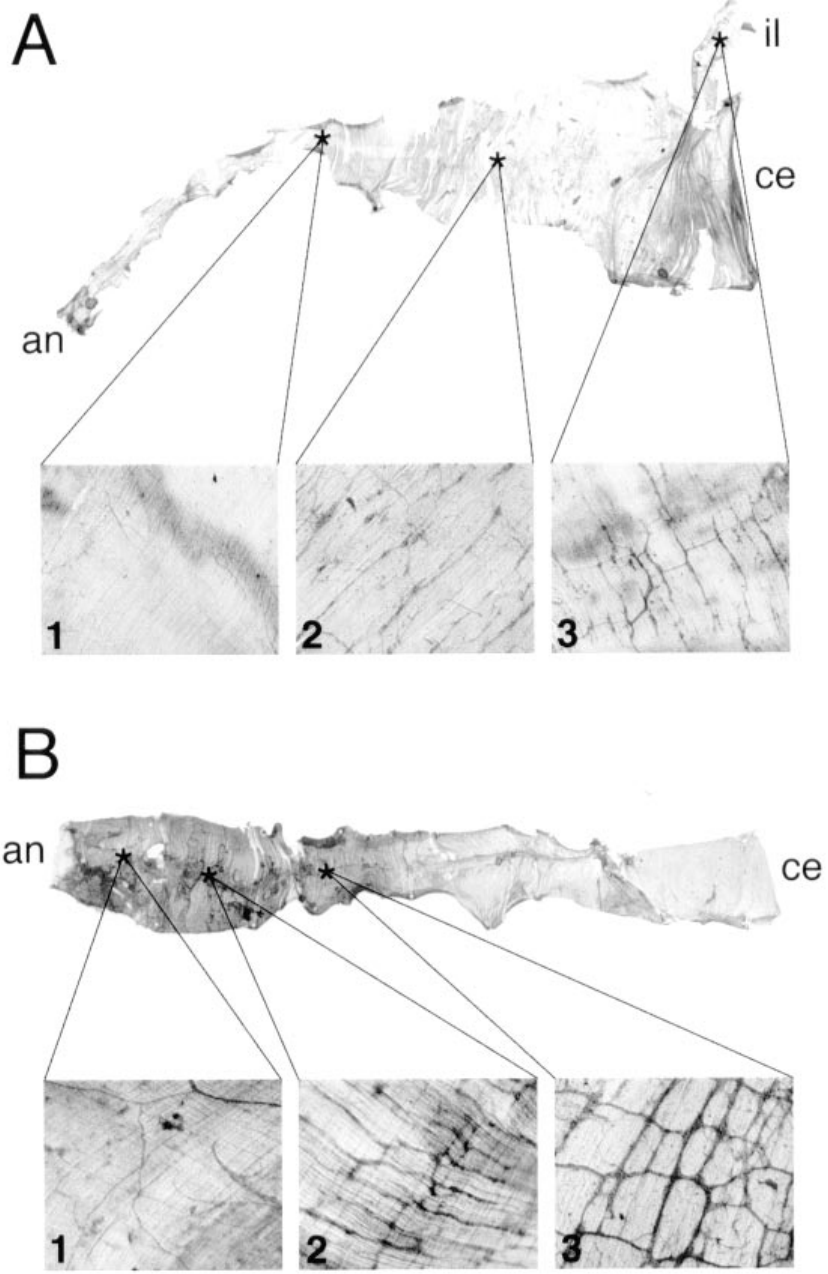

Figure 7. Length of aganglionic segment in $s / / s l$ non-transgenic and "partially rescued" $s / / s l$ transgenic rats. Wholemount acetylcholinesterase histochemistry on the entire colon. The colon has been opened along the mesenteric boarder and the mucosa has been removed to demonstrate the entire myenteric plexus. The anus (an), cecum (ce), and terminal ileum ( $i l)$ are indicated. $(A)$ An $s /$ sl non-transgenic rat colon fails to show a normal myenteric plexus throughout. A few scattered ganglion cells are identified, but the normal meshwork of ganglion cells is messing even from the distal small intestine (3). Note the very small caliber of the distal aganglionic colon, consistent with the description "microcolon." $(B)$ The same technique applied to the whole colon of an $s l / s l$ transgenic rat exhibiting signs of intestinal obstruction reveals a normal myenteric plexus extending into the distal one-third of the colon (3). The darker staining in the distal end of the specimen is the result of thickening of the intestinal wall. Also note the large caliber of the intestine distally.

cells migrate along the ventral pathway, and then enter the gut, and eventually colonize the whole length of the gut in a cranial-to caudal direction. Our in situ hybridization studies in rat embryos show that $E D N R B$ is expressed in cells populating the developing intestine in a cranial-to-caudal direction between E13.5 and E15.5. This pattern of expression is consistent with expression by the ENS precursors as they colonize the gut (45) and is consistent with the expression pattern found in avian and human embryos $(34,46)$.

Previous studies in Hirschsprung disease patients and in EDN3- or EDNRB-deficient rodent models of Hirschsprung 
disease suggest that an abnormal microenvironment in the distal developing intestine provides an unfavorable substrate for vagal crest colonization (47-54). There is evidence that the absence of EDNRB activation by EDN3 leads to increased expression of laminin that may result in premature differentiation of neural crest-derived cells and contribute to their incomplete colonization of the gut $(55,56)$. Aggregation chimera studies in mice suggest that activation of the EDNRB receptor on the colonizing neuroblasts leads to local environmental or extracellular signals, which promote colonization. Embryos formed as a chimera between wild-type mice carrying a $D \beta H$-nlacZ marker of the enteric neuroblasts, and $E D N R B$-deficient embryos allow the colonization success or failure of neuroblasts from wild-type and mutant animals to be examined in the same microenvironment.

In such studies, Kapur and colleagues found that neuroblasts from $E D N R B$-deficient mice could successfully colonize the distal gut when they were surrounded by a sufficient percentage of wild-type cells (57). If $E D N R B$ is expressed in the mouse, as it appears to be in humans, chicks, and rats, by the colonizing neuroblasts, then activation of the EDNRB receptor on wild-type neuroblasts may lead to changes in the microenvironment surrounding that cell. This microenvironmental change provides a signal favorable to gut colonization that can be transferred to nearby neuroblasts deficient in EDNRB. A direct connection between EDNRB activation and increased laminin is not yet identified. This intercellular "signal" can presumably be either a paracrine mediator such as a growth factor, or, literally, an environment such as an extracellular matrix.

However, because $E D N R B$ mRNA in situ hybridization studies in humans and rats indicate that during neuroblast colonization of the gut there is no distal expression of $E D N R B$, any microenvironmental effect of EDNRB activation is likely to be local to the neuroblasts themselves. This is in agreement with Newgreen and Hartley (1995) who studied the maturation of the rat gut mesenchyme in wild-type and $s l / s l$ embryos between E12.5 and E16.5. Although they identified an abnormality in the development of the neural crest-derived cells, they were unable to identify any abnormality in the development of the mesenchymal cells using a battery of immunohistochemical markers of extracellular matrix and cell adhesion molecules, including laminin.

The D $\beta H-E D N R B$ transgene "rescues" enteric neurons in $s l / s l$ rats. The activity of the $5.8-\mathrm{kb} D \beta H$ promoter is well defined in the mouse, where it has been used to target expression of several heterologous cDNAs $(39,41)$. It consistently drives transcription in the same spatial and temporal patterns in multiple lines of $D \beta H$-nlac $Z$ mice. In the mouse, the $D \beta H$ promoter activity begins in ENS precursors, as they reach the foregut and persists postnatally in a subset of enteric neurons. As the vagal crest cells colonize the gut in a cranial-to-caudal direction, the $D \beta H$ promoter is active in ENS precursors, the ventral neural tube, and various peripheral ganglia. These findings are consistent with the expression pattern of $D \beta H$ in the mouse determined by in situ hybridization. In addition, a small focus of expression has been noted in the mesenchyme of the medial face (39).

In the rat embryo, we found that expression of $E D N R B$ driven by the same fragment of the human $D \beta H$ promoter is seen not only in those cells predicted by the mouse $D \beta H$ $n l a c Z$ experiments, but also in several other tissues. Despite these areas of ectopic expression, there is no effect on the colonization of the epidermal melanoblasts; the coat color pattern of the $s l / s l$ transgenic animals is indistinguishable from $s l / s l$ non-transgenic animals, suggesting that the transgene maintains some level of restricted expression. The ectopic expression may be the result of species differences in transcriptional control. Although this small fragment of the human $D \beta H$ promoter may be sufficient to specifically direct expression in the mouse, it is apparently not sufficient to do so in rats. Alternatively, the $E D N R B$ cDNA used to create the transgene may alter the transcriptional regulation of the promoter. Finally, it is possible that the expression of the EDNRB receptors in some way alters the activity of the $D \beta H$ promoter.

The $D \beta H-E D N R B$ expression pattern is consistent with expression by the ENS precursors. By E15.5, the expression pattern is entirely consistent with expression by the myenteric and submucosal ganglion cells. Given the cranial-to-caudal pattern of $E D N R B$ expression in wild-type rats, it is likely that expression of $E D N R B$ in the neural crest-derived cells is responsible for the successful colonization of the distal intestine in these rats. However, double staining with ENS markers will be necessary to formally document transgene expression in the ENS precursors.

The D $\beta H$-EDNRB transgene's ability to prevent intestinal aganglionosis without affecting pigmentation suggests the critical timing of EDNRB expression necessary for ENS development. Neural crest cells migrate along two pathways as they leave the neural tube: $a$ ) a ventral pathway, through the somites or between the neural tube and the adjacent somite (3, $7-9,58)$, and $b$ ) a dorsolateral pathway, between the somite and the overlying ectoderm $(4,5)$. Cells following the ventral pathway give rise to neurons and glia of the peripheral nervous system, neuroendocrine cells, and pharyngeal arch-derived tissues of the face and neck. Neural crest-derived cells on the dorsolateral pathway give rise to epidermal melanocytes.

Endogenous wild-type $E D N R B$ expression is detected along the dorsolateral pathway of neural crest migration in E11.5 rat embryos consistent with EDNRB expression by the melanocyte precursors. However, expression of the $D \beta H-E D N R B$ transgene is undetectable along this pathway in early rat embryos. This suggests that the $D \beta H$ promoter does not direct expression to the melanoblast precursors and is supported by the finding that the pigmentary abnormalities of the $s l / s l$ rats are unaffected by expression of the $D \beta H-E D N R B$ transgene. The $D \beta H$-EDNRB transgene's failure to rescue pigmentation defects in $s l / s l$ rats suggests that it does not lead to EDNRB expression in the neural crest-derived cells until after the melanocyte and ENS lineages diverge. The $D \beta H-E D N R B$ transgene's ability to prevent intestinal aganglionosis shows that the critical time for $E D N R B$ expression in the developing rat ENS begins after the divergence of these two lineages.

The phenotypic effects of the D $\beta H$-EDNRB transgene are dose dependent. In the $D \beta H$-EDNRB transgenic line $1, \sim 20 \%$ of the $s l / s l$ rats hemizygous for the transgene and $5 \%$ of the $s l /$ $s l$ rats homozygous for the transgene exhibit intestinal aganglionosis. The occurrence of the disease is inversely related to the number of copies of the transgene that the $s l / s l$ rat carries. Furthermore, these transgenic, yet aganglionic animals, exhibit a "partial rescue" phenotype. First, they live significantly longer than non-transgenic $s l / s l$ rats, probably because they are able to pass a small amount of feces as evidenced by the soiling around the tail and anus. Second, the very distal nature of their 
intestinal obstruction is evident from the observation of a large amount of stool in the rectum. This visible rectal mass was never observed in non-transgenic $s l / s l$ rats. Finally, very short segment aganglionosis was demonstrated histologically in "partially rescued" rats. Our studies in non-transgenic rats are consistent with other reports in which normal ganglion cells were never demonstrated beyond the proximal colon in $s / / s l$ rats $(12,27)$.

In the transgenic line 1 , hemizygous $s l / s l$ adult rats express significantly less $E D N R B$ mRNA in the colon than non-transgenic $s l /+$ rats. We did not quantify the $E D N R B$ mRNA expression or receptor expression in the gut of transgenic $s l / s l$ embryos. If the adult expression levels are representative of the relative expression levels in the transgene hemizygous $s l / s l$ and non-transgenic $s l+$ embryos, then it is very likely that the "partial rescue" phenotype results from low level embryonic expression of $E D N R B$ falling near a threshold amount necessary for normal ENS development. This is further supported by the much higher rate of complete rescue in the $\mathrm{sl} / \mathrm{sl}$ rats homozygous for the transgene. This threshold for normal colonization is reminiscent of three other circumstances, in which a dosage effect has been observed in EDNRB signaling.

First, an $E D N R B$ dosage effect is noted in animals carrying a naturally occurring hypomorphic mutation in the $E D N R B$ gene, piebald (59). Mice homozygous for the piebald $(s / s) \mathrm{mu}-$ tation express $E D N R B$ mRNA and protein at $25 \%$ the level of homozygous wild-type mice by Northern blot and radioligandbinding analysis, respectively (23). The reduced expression of the piebald $E D N R B$ is the result of disruption of enhancer elements within the first intron of the EDNRB gene (our unpublished observations). Whereas mice homozygous for a null mutation of $E D N R B$ always exhibit intestinal aganglionosis, $s / s$ mice rarely show intestinal aganglionosis. Interestingly, compound heterozygous mice $(s /-)$ exhibit distal intestinal aganglionosis in $\sim 19 \%$ of pups (our unpublished observations) (10). The compound heterozygous mice have been shown by Northern analysis to express $12.5 \%$ the level of EDNRB mRNA as wild-type mice. These observations indicate that in these mice, the threshold level of EDNRB expression for complete colonization of the hindgut is between 12.5 and $25 \%$ of the wild-type $E D N R B$ expression level. The relative length of intestinal aganglionosis in these mutation mice has not been carefully studied.

Second, a threshold effect was observed by Kapur and colleagues (1995) in a mouse aggregation chimera study. The colonization-promoting effect of EDNRB activation was non-cell autonomous and depended on the percentage of EDNRBexpressing cells in the chimeric animal. Wild-type neuroblasts failed to colonize the hindgut in chimeric mice with a high percentage of mutant cells, whereas mutant neuroblasts successfully colonized the hindgut in chimeric mice with a high percentage of wild-type cells. This suggests that the putative microenvironmental signal produced in response to activation of the EDNRB receptor exhibits a critical threshold effect on the neuroblasts (57).

Third, in an inbred human population, Puffenberger and colleagues (1994) demonstrated that an $E D N R B$ mutation acts in a dose-dependent manner to modulate the incidence of Hirschsprung disease, although an effect on the length of aganglionosis was not carefully examined in this study.

The EDNRB activation threshold is likely to vary significantly in different genetic backgrounds and species. This is particularly relevant in Hirschsprung disease. Heterozygous and homozygous mutations of EDN3 or EDNRB causing sporadic Hirschsprung disease are, in most cases, incompletely penetrant. Furthermore, Hirschsprung disease shows wide variability in length of aganglionic bowel with increasing recognition of "ultra-short" segment disease. This is the first study to correlate the occurrence and variation in the length of intestinal aganglionosis to the dosage of a single gene. The "partial rescue" phenotype demonstrated in this rodent model indicates that intestinal aganglionosis can occur on a continuum related to the activity of the single gene or gene product.

\section{Acknowledgments}

We thank Raj Kapur for helpful discussions.

M. Yanagisawa is an Investigator and C.E. Gariepy is an Associate of the Howard Hughes Medical Institute. This work is supported in part by research grants from the Perot Family Foundation, the W.M. Keck Foundation, and the Tanabe Medical Frontier Conference. C.E. Gariepy is a recipient of the Glaxo Wellcome Institute for Digestive Health Basic Science Research Award.

\section{References}

1. Rawles, M. 1940. The development of meanophores from embryonic mouse tissues grown in the coelom of chick embryos. Proc. Natl. Acad. Sci. USA. 26:673-680.

2. Rawles, M. 1947. Origin of pigment cells from the neural crest in the mouse embryo. Physiol. Zool. 20:248-270.

3. Le Douarin, N.M., and M. Teillet. 1973. The migration of neural crest cells to the wall of the digestive tract in avian embryo. J. Embryol. Exp. Morphol. 30:31-48.

4. Mayer, T. 1973. The migratory pathway of neural crest cells into the skin of mouse embryos. Dev. Biol. 34:39-46.

5. Serbedzija, G., S. Fraser, and M. Bronner-Fraser. 1990. Pathways of trunk neural crest cell migration in the mouse embryo as revealed by vital dye labeling. Development. 108:605-612.

6. Webster, W. 1973. Embryogenesis of the enteric ganglia in normal mice and mice that develop congenital aganglionic megacolon. J. Embryol. Exp. Morph. 30:573-585.

7. Yntema, C.L., and W.S. Hammond. 1954. The origin of intrinsic ganglia of trunk viscera from vagal neural crest in the chick embryo. Neurology. 101: $515-542$.

8. Kapur, R.P., C. Yost, and R.D. Palmiter. 1992. A transgenic model for studying development of the enteric nervous system in normal and aganglionic mice. Development. 116:167-175.

9. Peters-van der Sanden, M.J., M.L. Kirby, A. Guttenberger-de Groot, D. Tibboel, M.P. Mulder, and C. Meijers. 1993. Colonization of the bowel by neural crest-derived cells re-migrating from foregut backtransplanted to vagal or sacral regions of host embryos. Dev. Dyn. 196:217-233.

10. Lane, P.W. 1966. Association of megacolon with two recessive spotting genes in the mouse. J. Hered. 57:28-31.

11. Lyon, M., and A. Searle. 1989. Genetic Variants and Strains of the Laboratory Mouse. Oxford University Press, Oxford, UK.

12. Ikadai, H., H. Fujita, Y. Agematsu, and T. Imanichi. 1979. Observation of congenital aganglionosis rat (Hirschsprung's disease) and its genetical analysis. (in Japanese). Congenital. Anom. 19:31-36.

13. McCabe, L., L. Griffin, A. Kinzer, M. Chandler, J. Beckwith, and E. McCabe. 1990. Overo lethal white foal syndrome: equine model of aganglionic megacolon (Hirschsprung disease). Am. J. Med. Genet. 36:336-340.

14. Shah, K., S. Dalal, M. Desai, P. Sheth, N. Joshi, and L. Ambani. 1981. White forelock, pigmentary disorder of irides, and long segment Hirschsprung disease: possible variant of Waardenburg syndrome. J. Pediatr. 99:432-435.

15. Edery, P., T. Attie, J. Amiel, A. Pelet, C. Eng, R. Hofstra, Martelli, C. Bidaud, A. Munnich, and S. Lyonnet. 1996. Mutation of the endothelin-3 gene in Waardenburg-Hirschsprung disease (Shah-Waardenburg Syndrome). Nat. Genet. 12:442-444.

16. Attie, T., M. Till, A. Pelet, J. Amiel, P. Edery, L. Bautrand, A. Munnich, and S. Lyonnet. 1995. Mutation of the endothelin-receptor B gene in Waardenburg-Hirschsprung disease. Hum. Mol. Genet. 4:2407-2409.

17. Auricchio, A., G. Casari, A. Staiano, and A. Ballabio. 1996. Endothelin-B receptor mutations in patients with isolated Hirschsprung disease from a noninbred population. Hum. Mol. Genet. 5:351-354.

18. Amiel, J., T. Attie, D. Jan, A. Pelet, P. Edery, C. Bidaud, D. Lacombe, P. Tam, J. Simeoni, E. Flori, et al. 1996. Heterozygous endothelin receptor B 
(EDNRB) mutations in isolated Hirschsprung disease. Hum. Mol. Genet. 5: 355-357.

19. Hofstra, R.M.W., J. Osinga, G. Tan-Sindhunata, Y. Wu, E.-J. Kamsteeg, R.P. Stulp, C.V. Ravenswaaij-Arts, D. Majoor-Krakauer, M. Angrist, A. Chakravarti, C. Meijers, and C.H.C.M. Buys. 1996. A homozygous mutation in the endothelin-3 gene associated with a combined Waardenburg type 2 and Hirschsprung phenotype (Shah-Waardenburg syndrome). Nat. Genet. 12:445-447.

20. Puffenberger, E.G., K. Hosoda, S.S. Washington, K. Nakao, D. deWit, M. Yanagisawa, and A. Chakravarti. 1994. A missense mutation of the endothelin-B receptor gene in multigenic Hirschsprung disease. Cell. 79:1257-1266.

21. Kusafuka, T., Y. Wang, and P. Puri. 1996. Novel mutations of the endothelin-B receptor gene in isolated patients with Hirschsprung's disease. Hum. Mol. Genet. 5:347-349.

22. Baynash, A.G., K. Hosoda, A. Giaid, J.A. Richardson, N. Emoto, R.E. Hammer, and M. Yanagisawa. 1994. Interaction of endothelin-3 with endothelin-B receptor is essential for development of neural crest-derived melanocytes and enteric neurons: missense mutation of endothelin-3 gene in lethal spotting mice. Cell. 79:1277-1285.

23. Hosoda, K., R.E. Hammer, J.A. Richardson, A. Greenstein Baynash, J.C. Cheung, A. Giaid, and M. Yanagisawa. 1994. Targeted and natural (piebald-lethal) mutations of endothelin-B receptor gene produce aganglionic megacolon associated with white-spotted coat color in mice. Cell. 79:1267-1276.

24. Yanagisawa, H., M. Yanagisawa, R. Kapur, J. Richardson, S. Williams, D. Clouthier, D. de Wit, N. Emoto, and R. Hammer. 1998. Dual genetic pathways of endothelin-mediated intercelluar signaling revealed by targeted disruption of endothelin convertin enzyme-1 gene. Development. 125:825-836.

25. Santschi, E., A. Purdy, S. Valberg, P. Vrotsos, H. Kaese, and J. Mickelson. 1998. Endothelin receptor B polymorphism associated with lethal white foal syndrome in horses. Mamm. Genome. 9:306-309.

26. Gariepy, C.E., D.T. Cass, and M. Yanagisawa. 1996. Null mutation of endothelin-B receptor gene in spotting lethal rats causes aganglionic megacolon and white coat color. Proc. Natl. Acad. Sci. USA. 93:867-872.

27. Nagahama, M., T. Ozaki, and K. Hama. 1985. A study of the myenteric plexus of the congenital aganglionosis rat (spotting lethal). Anat. Embryol. 171: 285-296.

28. Yanagisawa, M., H. Kurihara, S. Kimura, Y. Tomobe, M. Kobayashi, Y. Mitsui, Y. Yazaki, K. Goto, and T. Masaki. 1988. A novel potent vasoconstrictor peptide produced by vascular endothelial cells. Nature. 332:411-415.

29. Yanagisawa, M. 1994. The endothelin system: a new target for therapeutic intervention. Circulation. 89:1320-1322.

30. Sokolovsky, M. 1994. Endothelins and sarafotoxins: receptor heterogeneity. Int. J. Biochem. 26:335-340.

31. Sakamoto, A., M. Yanagisawa, T. Sawamura, T. Enoki, T. Ohtani, T. Sakurai, K. Nakao, T. Toyo-oka, and T. Masaki. 1993. Distinct subdomains of human endothelin receptors determine their selectivity to ETA-selective antagonist and ETB-selective agonists. J. Biol. Chem. 268:8547-8553.

32. Arai, H., S. Hori, I. Aramori, H. Ohkubo, and S. Nakanishi. 1990. Cloning and expression of a cDNA encoding an endothelin receptor. Nature. 348: 730-732.

33. Sakurai, T., M. Yanagisawa, Y. Takuwa, H. Miyazaki, S. Kimura, K. Goto, and T. Masaki. 1990. Cloning of a cDNA encoding a non-isopeptideselective subtype of the endothelin receptor. Nature. 348:732-735.

34. Brand, M., J.-M. Le Moullec, P. Corval, and J.-M. Gasc. 1998. Ontogeny of endothelins- 1 and -3 , their receptors, and endothelin converting enzyme- 1 in the early human embryo. J. Clin. Invest. 101:549-559.

35. Baetge, G., and M.D. Gershon. 1988. Transient catecholaminergic (TC) cells in the vagus nerves and bowel of fetal mice: relationship to the development of enteric neurons. Dev. Biol. 132:189-211.

36. Baetge, G., J.E. Pintar, and M.D. Gershon. 1990. Transiently catecholaminergic (TC) cells in the bowel of fetal rats and mice: precursors of non-catecholaminergic enteric neurons. Dev. Biol. 141:353-380.

37. Baetge, G., K.A. Schneider, and M.D. Gershon. 1990. Development and persistence of catecholaminergic neurons in cultured explants of fetal murine vagus nerves and bowel. Development. 110:689-701.

38. Blaugrund, E., T.D. Pham, V.M. Tennyson, L. Lo, L. Sommer, D.J. Anderson, and M.D. Gershon. 1996. Distinct subpopulations of enteric neuronal progenitors defined by time and place of development, sympathoadrenal lineage markers and Mash-1-dependence. Development. 122:309-320.

39. Kapur, R.P., G.W. Hoyle, E.H. Mercer, R.L. Brinster, and R.D. Palmiter. 1991. Some neuronal cell populations express human dopamine $\beta$-hydroxylase-lacZ transgenes transiently during embryonic development. Neuron. 7:
$717-727$.

40. Clouthier, D., K. Hosoda, J. Richardson, S. Williams, H. Yanagisawa, T. Kuwaki, M. Kumada, R. Hammer, and M. Yanagisawa. 1998. Cranial and cardiac neural crest defects in endothelin-A receptor-deficient mice. Development. 125:813-824.

41. Hoyle, G.W., E.H. Mercer, R.D. Palmiter, and R.L. Brinster. 1993. Expression of NGF in sympathetic neurons leads to excessive axon outgrowth from ganglia but decreased terminal innervation within tissues. Neuron. 10: 1019-1034.

42. Hammer, R., S. Maika, J. Richardson, J.-P. Tang, and J. Taurog. 1990. Spontaneous inflammatory disease in transgenic rats expression HLA-B27 and human $32 \mathrm{~m}$ : an animal model of HLA-B27-associated human disorders. Cell. 63:1099-1112.

43. Xu, D., N. Emoto, A. Giaid, C. Slaughter, S. Kaw, D. de Wit, and M. Yanagisawa. 1994. ECE-1: a membrane-bound metalloprotease that catalyzes the proteolytic activation of big endothelin-1. Cell. 78:473-485.

44. Newgreen, D., and L. Hartley. 1995. Extracellular matrix and adhesive molecules in the early development of the gut and its innervation in normal and spotting lethal rat embryos. Acta Anat. 154:243-260.

45. Watanabe, Y., T. Harada, T. Ito, Y. Ishiguro, H. Ando, T. Seo, S. Kobayashi, M. Takahashi, and Y. Nimura. 1997. ret proto-oncogene product is a useful marker of lineage determination in the development of the enteric nervous system in rats. J Pediatr Surg. 32:28-33.

46. Nataf, V., L. Lecoin, A. Eichmann, and N.M. Le Douarin. 1996. Endothelin-B receptor is expressed by neural crest cells in the avian embryo. Proc. Natl. Acad. Sci. USA. 93:9645-9650.

47. Payette, R., V. Tennyson, H. Pomeranz, T. Pham, T. Rothman, and M. Gershon. 1988. Accumulation of components of basal laminae: association with the failure of neural crest cells to colonize the presumptive aganglionic bowel of ls.ls mutant mice. Dev. Biol. 125:341-360.

48. Watanabe, Y., T. Ito, S. Iino, T. Harada, H. Ando, T. Seo, S. Kobayashi, and T. Ozaki. 1997. Unique spindle cells in the involved ileal segment of rats with congenital aganglionosis. J. Pediatr. Surg. 32:1229-1233.

49. Shimotake, T., N. Iwai, J. Yanagihara, E. Deguchi, and S. Fushiki. 1995. Impared proliferative activity of mesenchymal cells affects the migratory pathway for neural crest cells in the developing gut of mutant murine embryos. $J$. Pediatr. Surg. 30:445-447.

50. Langer, J., P. Betti, and M. Blennerhassett. 1994. Smooth muscle from aganglionic bowel in Hirschsprung's disease impairs neuronal development in vitro. Cell Tissue Res. 276:181-186.

51. Parikh, D., P. Tam, D. Van Velzen, and D. Edgar. 1992. Abnormalities in the distribution of laminin and collagen type IV in Hirschsprung's disease. Gastroenterology. 102:1236-1241.

52. Parikh, D., P. Tam, D. Lloyd, D. Van Velzen, and D. Edgar. 1992. Quantitative and qualitative analysis of the extracellular matrix protein, laminin, in Hirschsprung's disease. J. Pediatr. Surg. 27:991-995.

53. Jacobs-Cohen, R., R. Payette, M. Gershon, and T. Rothman. 1987. Inability of neural crest cells to colonize the presumptive aganglionic bowel of ls ls mutant mice: requirement for a permissive microenvironment. J. Comp. Neurol. $255: 425-438$.

54. Rothman, T., D. Goldowitz, and M. Gershon. 1993. Inhibition of migration of neural crest-derived cells by the abnormal mesenchyme of the presumptive aganglionic bowel of ls/ls mice: analysis with aggregation and interspecies chimeras. Dev. Biol. 159:559-573.

55. Pomeranz, H., T. Rothman, A. Chalazonitis, V. Tennyson, and M. Gershon. 1993. Neural crest-derived cells isolated from the gut by immunoselection develop neuronal and glial phenotypes when cultured on laminin. Dev Biol. 156:341-361.

56. Chalazonitis, A., V. Tennyson, M. Kibbey, T. Rothman, and M. Gershon. 1997. The $\alpha 1$ subunit of laminin-1 promotes the development of neurons by interacting with LBP110 expressed by neural crest-derived cells immunoselected from the fetal mouse gut. J. Neurobiol. 33:118-138.

57. Kapur, R.P., D.A. Sweetser, B. Doggett, J.R. Siebert, and R.D. Palmiter. 1995. Intercellular signals downstream of endothelin receptor-B mediate colonization of the large intestine by enteric neuroblasts. Development. 121: 3787-3795.

58. Rothman, T.P., and M.D. Gershon. 1982. Phenotypic expression in the developing murine enteric nervous system. J. Neurosci. 2:381-393.

59. Silvers, W. 1979. The Coat Colors of Mice: A Model for Mammalian Gene Action and Interaction. Springer-Verlag, Inc., New York. 